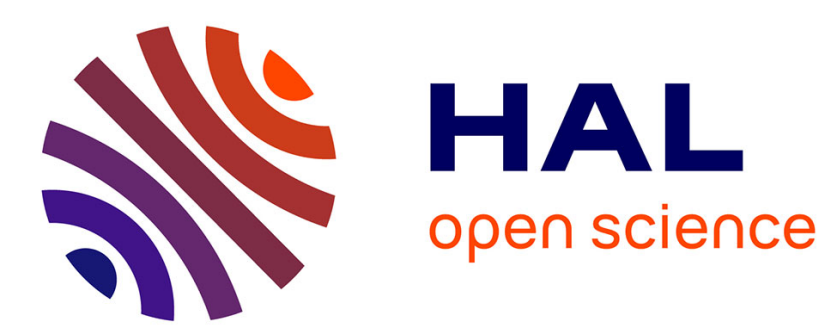

\title{
3-D printing solar photovoltaic racking in developing world
}

\author{
Ben T Wittbrodt, Joshua Pearce
}

\section{To cite this version:}

Ben T Wittbrodt, Joshua Pearce. 3-D printing solar photovoltaic racking in developing world. Energy for Sustainable Development, 2017, 36, pp.1-5. 10.1016/j.esd.2016.08.001 . hal-02113479

\section{HAL Id: hal-02113479 https://hal.science/hal-02113479}

Submitted on 28 Apr 2019

HAL is a multi-disciplinary open access archive for the deposit and dissemination of scientific research documents, whether they are published or not. The documents may come from teaching and research institutions in France or abroad, or from public or private research centers.
L'archive ouverte pluridisciplinaire HAL, est destinée au dépôt et à la diffusion de documents scientifiques de niveau recherche, publiés ou non, émanant des établissements d'enseignement et de recherche français ou étrangers, des laboratoires publics ou privés. 
Preprint: B.T. Wittbrodt \& J.M. Pearce. 3-D printing solar photovoltaic racking in developing world. Energy for Sustainable Development 36, pp. 1-5 (2017). DOI:10.1016/j.esd.2016.08.001

\title{
3-D Printing Solar Photovoltaic Racking in Developing World
} Ben Wittbrodt ${ }^{1}$ and Joshua M. Pearce ${ }^{1,2, *}$

1. Department of Materials Science \& Engineering, Michigan Technological University

2. Department of Electrical \& Computer Engineering, Michigan Technological University

* Corresponding author

601 M\&M Building

1400 Townsend Drive

Houghton, MI 49931-1295

906-487-1466

pearce@mtu.edu

\begin{abstract}
The purpose of this paper is to provide a technical and economic evaluation of the value of the RepRap as an entry-level 3-D printer in the developing world and provide a cost effective solar photovoltaic (PV) racking solution to better serve the developing world and aid in the acceleration of their economic and socioeconomic growth. A customizable open-source PV racking concept is designed, prototyped for three types of modules, constructed into systems, and outdoor tested under extreme conditions for one year. An economic analysis is provided along with a technical evaluation of the system, which found the proposed racking system can be successfully printed with RepRap 3-D printers and saves between $85 \%$ and $92 \%$ from commercially available alternatives depending on the plastic used for printing. In addition, the plastic parts proved able to withstand some of the harshest outdoor conditions and due to the free and open-source nature of the designs, it allows the system to be adapted to custom applications in any region in the world more easily than any commercial alternatives. The results indicate that the 3-D printable X-wire solar photovoltiac racking system has the potential to aid in the acceleration of solar deployment in the developing world by providing a low cost PV racking solution.
\end{abstract}

Keywords: Developing world; 3-D Printing; Sustainable Development; Open-source; photovoltaic; racking

\section{Introduction}

Various additive manufacturing technologies has been used in industry to prototype new products for decades (Yan and Gu, 1996; Pham and Gault, 1998;Kruth et al., 1998; Leu et al., 2012; Mitsuishi et al., 2013), but until the introduction of the RepRap project (Self- 
Replicating Rapid Prototyper) brought entry level devices s to the market, 3-D printing was not a realistic purchase for most households. The RepRap project aims to provide a cost effective 3-D printer based on open-source software and libre hardware that encourages collaboration between many people throughout the world (Jones et al., 2011). This allows a greater number of people to both contribute to and benefit from the project simultaneously (Jones et al., 2011). Currently, an entry-level RepRap can be built near, or below, $\$ 500$ in parts (Wittbrodt et al., 2013) with costs continuing to decline as the popularity of 3-D printing rises (Wohlers Associates, 2013). These price declines are moving the technology from an industry specific technology to one that could be used in the developing world (Pearce et al., 2010; Campbell et al., 2011; Lipson and Kurman, 2013; Tanenbaum et al., 2013).

Current estimates of the world's poor show that the issue of poverty is a much greater threat than initially thought and it is imperative that efforts are made to increase the standard of living (Chen and Ravallion, 2008). Today it is estimated that 2.6 billion without any sanitation (Dugger, 2006) and for cooking, 2.5 billion people are forced to use biomass, fuel wood, charcoal, or animal dung as energy in order to eat (Shah, 2013). In addition, over 2 billion people live without access to electricity (Reiche et al., 2000), For example, with only $0.2 \%$ of rural areas in Zimbabwe having access to the grid the cost of extending the grid hinder the growth and development of the country (Drennen et al., 1996). As efforts are made to develop other areas of the world, with electrification for example, it is important to utilize sustainable development practices to reduce the future impact of a greater number of developing areas (Drennen et al., 1996).

Access to electricity has been shown to accelerate development (Reiche et al., 2000) and being able to use basic electric appliances (e.g. lighting, water pumps, cell phones) can springboard development with improvements to education, sanitation, nutrition, and industry (Reiche et al., 2000; Kanagawa and Nakata, 2008). 3-D printers can be one of the electrical appliances and further their ability to develop and produce needed items and replace broken components of a large variety of systems with specialized parts that would otherwise be unavailable (Pearce et al., 2010). One technology that has been shown to be particularly useful in sustainable electrification of rural developing communities is solar photovoltaic (PV) technology (Acker and Kammen, 1996; Pearce, 2002).

Although PV prices have dropped considerably (Branker et al., 2011), one of the remaining fixed costs that have not declined is the relative cost of the balance of systems (BOS) related to the total cost of a PV array (Fthenakis and Alsema, 2006). The BOS includes racking, wiring and electronics necessary to complete a PV system. Hence, for PV to be competitive with traditional energy generation methods, more work must be done to reduce manufacturing PV costs and BOS costs (Lewis, 2007). One way presented to decrease the BOS costs is utilizing low-cost distributed manufacturing with a RepRap 3-D printerfor small-scale mobile PV arrays (Wittbrodt et al., 2014).

This study evaluates the technical and economic viability of distributed manufacturing of PV racking in the developing world using entry-level RepRap 3-D printers. A 
customizable open-source PV racking concept is designed, prototyped for three types of modules, constructed into a system, and outdoor tested under extreme conditions for one year. The technical viability of using commercial 3-D printer filament and recycled plastic waste is determined for outdoor use in this application. Finally, a detailed economic analysis is performed.

\section{Methods and Materials}

A ground-mounted PV racking system was designed in OpenSCAD 2014.03 (OpenSCAD, 2014) a free and open-source solid modeling program, using parametric variables that automatically manipulate the entire part to enable simple modifications without the need for knowledge in 3-D modeling. These OpenSCAD code generates 12 different STL files for all the potential geometries of an infinite scaled array. The STL files were sliced in the open-source Cura (Ultimaker, 2014) before printing with solid 100\% infill on a MOST Prusa RepRap (MOST, 2014) using Repetier-Host (Repetier, 2014) to drive the printer. Once the parts were completed threaded steel rods were inserted into the parts for added strength and support and tightened down with nuts. Steel wire was threaded through the mounting brackets in a X shaped pattern under the modules to tensions the modules together giving name to the system of $\mathrm{X}$-wire. The detailed bill of materials (BOM) needed to assemble the X-wire system can be found in Table 1, including the cost of the tools. 
Table 1:

BOM of the $1 \mathrm{~kW}$ assembled $\mathrm{X}$-wire system

\begin{tabular}{lllcrlrr}
\hline & & \multicolumn{9}{c}{ Bill of Materials } & & & & \\
\hline Type & Item name & Source & Item No. & Quantity & Unit & $\$ /$ Qty. & Price per item \\
\hline Metal & M8 Rod & McMaster & 90024A080 & 1.25 & Meter & $\$ 8.31$ & $\$ 10.39$ \\
& Steel Wire & McMaster & 8908T66 & 11.88 & Meter & $\$ 2.76$ & $\$ 32.74$ \\
& Hex Nuts & McMaster & 91828A410 & 18 & Count & $\$ 0.20$ & $\$ 3.60$ \\
\hline Plastic & PLA Filament & Prototype Supply & 3mm Silver & 1.5 & Kg & $\$ 36.00$ & $\$ 54.00$ \\
\hline Tools & 13mm Wrench & McMaster & 71405A38 & 1 & Count & $\$ 10.98$ & $\$ 10.98$ \\
\hline
\end{tabular}

The OpenSCAD design includes parametric variables that allow quick and easy changes to the module tilt angle and size of the module as shown in Figure 1. Pictured are two brackets setup for 10 degrees of tilt and 20 degrees of tilt showing the difference in the cup angle and height. Each bracket is paired with an extension bar of appropriate height as well. If the user decides to expand the PV array in the future additional parts can be printed out to fit the new modules and simply added to the existing array. It is also possible to use this system on every framed PV module whether it be a smaller mobile module (GoalZero, 2014), or large full-scale modules used here (Sharp, 2014). 


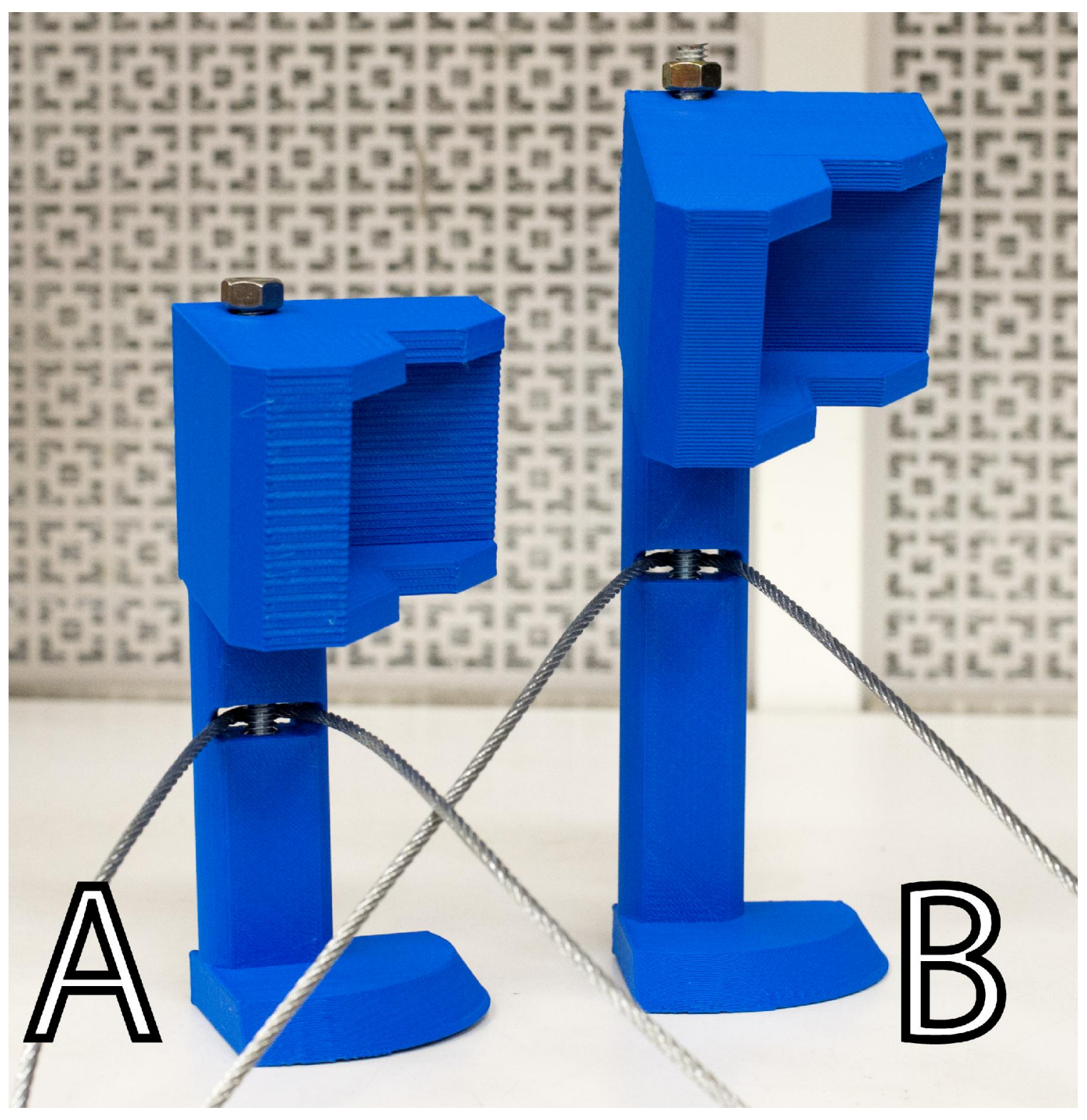

Figure 1: a) 10 degree and b) 20 degree tilt angle x-wire 3-D printed brackets fully assembled. Those shown here are for the back corners of the array. The cups in the upper portion of the brackets hold the corners of the PV modules.

Once the parts were printed and fit for the modules the racking system was assembled and placed outside and the brackets were tied down with more wire and tent stakes to ensure the modules did not lift off the ground due to wind loads.

The brackets were subjected to outdoor weather conditions for one year to validate the 
resilience of the parts. The parts were massed and the printing time was monitored to evaluate the cost of production. A 10 degree tilt system was used for analysis but a sample bracket at 20 degrees was printed to prove the customizability of the design (as shown in Figure 1). Following the printing and assembly a detailed economic analysis was performed comparing the Unirac RM (Unirac, 2014) racking system to the X-wire system when printed in commercially available polylactic acid (PLA) and recycled high density polyethylene (HDPE) filament. The Unirac system is advertised as one of the easiest and quickest racking systems to setup. While it is a roof mounted system it can be ballasted on the ground or easily staked into the ground to properly secure the RM system. Additionally the outdoor material behavior was examined theoretically using available literature on UV degradation and resilience of common 3-D printable materials.

\section{Results}

A 1kW PV array consisting of four $250 \mathrm{~W}$ PV modules, was successfully constructed, as shown in Figure 2, using the X-wire system. The array was deployed outside for the winter of 2013/2014 in the upper peninsula of Michigan and subjected to harsh temperatures and heavy snow loads as measured by the Keweenaw Research Center (KRC) (2014), where the system was setup. Once the snow fell the temperature at the level of the racking was between $19^{\circ} \mathrm{F}\left[-7.22^{\circ} \mathrm{C}\right]$ and $24^{\circ} \mathrm{F}\left[-4.44^{\circ} \mathrm{C}\right]$ for the duration of winter and had a maximum depth of snow of 39 inches [0.99 meters]. With a ground snow load of $100 \mathrm{lbs} / \mathrm{ft}^{2}$ [488.2 $\left.\mathrm{kg} / \mathrm{m}^{2}\right]$ (Energy, 2010) an estimate of the snow load on the 10 degree tilted modules is $84 \mathrm{lbs} / \mathrm{ft}^{2}$ [410.12 kg/m²] (Ochshorn, 2009). All 100\% fill parts remained in tact.

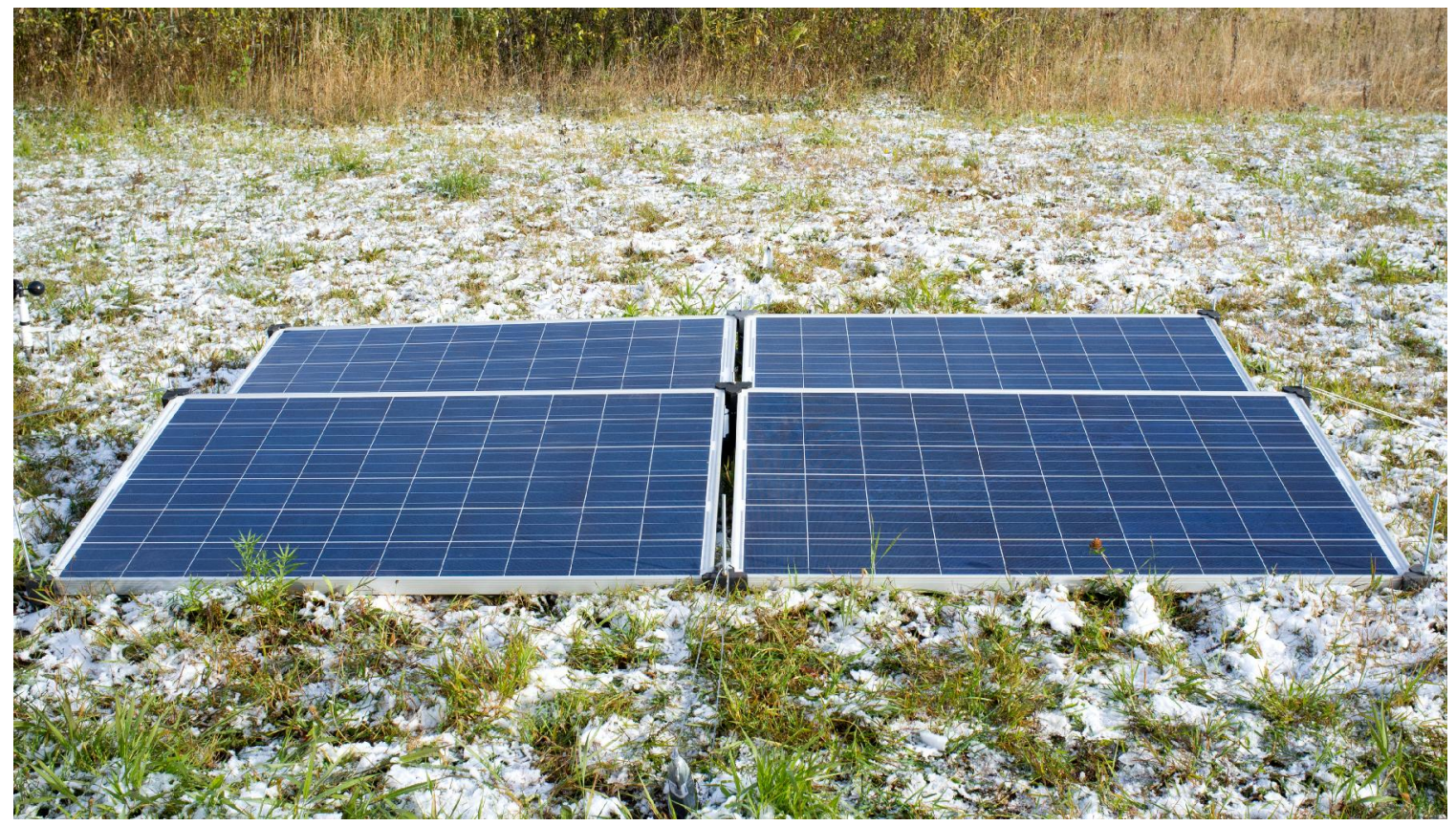

Figure 2: $\quad$ Assembled 1kW PV array with X-wire system. The 3-D printed 
components are shown in grey in Figure 2 are at the corners. The wiring forms an $\mathrm{x}$ pattern beneath the modules.

When compared to a commercial racking system the X-wire system is significantly less expensive with a savings of $83 \%$ (with commercial PLA) to 92\% (with recycled HDPE) as shown in Table 2, which does not include import duties. With the X-wire system the largest individual cost is the printed plastic with $1.5 \mathrm{~kg} / \mathrm{kW}$ used at $\$ 33$ per $\mathrm{kg}$. Using a new technology, the Recyclebot (Baechler et al., 2013), which converts waste plastic to 3-D printer feedstock the cost of the X-wire system can be lowered even further. The material cost from a Recyclebot are only \$0.10 USD per kg (Kreiger et al., 2014) when labor is excluded. Thus using Recyclebot filament will result in a total cost of \$47.07 USD for the X-wire system, a savings of $92 \%$ from the commercial racking alternative and a 51\% savings when compared to the PLA plastic X-wire system. Recyclebot extruded filament is particularly applicable in the developing world as there has already been efforts to create ethical filament standards (Feeley, et al., 2014), which would allow waste pickers to lift themselves out of poverty by capturing a larger share of the value from recycling plastics into 3-D printer filament.

Table 2: Cost breakdown of commercial racking and X-wire racking systems. Unirac RM

\begin{tabular}{lrrr}
\hline Item & Quantity & Price/count & Cost \\
\hline Ballast Bay & 9 & $\$ 58.12$ & $\$ 523.08$ \\
Clip & 24 & $\$ 1.54$ & $\$ 36.96$ \\
Hex Bolt & 24 & $\$ 0.65$ & $\$ 15.60$ \\
\hline & & Total & $\$ 575.64$
\end{tabular}

X-wire - Commercial PLA filament

\begin{tabular}{lrlrr}
\hline Item & Quantity & Unit & Price/count & Cost \\
\hline M8 Rod & 1.2735 & meter & $\$ 8.31$ & $\$ 10.58$ \\
Steel Wire & 11.88 & meter & $\$ 2.76$ & $\$ 32.74$ \\
M8 Nut & 18 & count & $\$ 0.20$ & $\$ 3.60$ \\
Plastic & 1.5 & $\mathrm{~kg}$ & $\$ 33.00$ & $\$ 49.50$ \\
\hline & & & Total & $\$ 96.42$
\end{tabular}

X-Wire - Recyclebot Filament

\begin{tabular}{lrlrr}
\hline Item & Quantity & Unit & Price/count & Cost \\
\hline M8 Rod & 1.2735 & meter & $\$ 8.31$ & $\$ 10.58$ \\
Steel Wire & 11.88 & meter & $\$ 2.76$ & $\$ 32.74$ \\
M8 Nut & 18 & count & $\$ 0.20$ & $\$ 3.60$ \\
Plastic & 1.5 & $\mathrm{~kg}$ & $\$ 0.10$ & $\$ 0.15$ \\
\hline
\end{tabular}


Typically aluminum is used with PV racking due to the strength and outdoor resilience but printed PLA plastic has been shown to be sufficiently strong in appropriate designs when compared to typical PLA properties (Tymrak et al., 2014). Tensile yield strength for the 6063 aluminum alloy used in the Unirac system is $145 \mathrm{MPa}$ (ASM, 2014) and an experimental value for printed PLA tensile strength is 56.6 MPa (Tymrak et al., 2014). Using the expression for tensile strength in equation 1 and equating the forces of fracture for PLA and aluminum it is possible to estimate the increase in cross-sectional area required for a PLA part to withstand the same force as an aluminum part:

$$
\sigma=\frac{F}{A}
$$

where, $\sigma$ is the tensile strength, $\mathrm{F}$ is the force applied, and $\mathrm{A}$ is the cross sectional area. The Unirac RM technical data sheet (Unirac, 2014) specifies that the ballast tray is $2.54 \mathrm{~mm}$ thick with a cross-sectional area of $215.48 \mathrm{~mm}^{2}$. Using equation 1 and the yield strength for aluminum, negating geometrical strengthening, the estimated force at fracture for 6063 aluminum is $31.24 \mathrm{kN}$. The $\mathrm{X}$-wire system has a cross-sectional area of 660 $\mathrm{mm}^{2}$ in the supports and using equation 1 again along with the tensile strength of PLA the ultimate force of $37.36 \mathrm{kN}$ can be withstood by the plastic alone. With the addition of the steel bar the X-wire system is able to perform adequately within the test environment and withstand the elements outdoors over the testing period.

\section{Discussion}

The entire PV racking system can be manufactured in the communities of the developing world using an entry-level RepRap 3-D printer. This enables total control over the entire process and the design of the PV racking by the end user to suit their needs depending on geographic location, cultural sensitivities and potential weather concerns. An additional benefit to distributed manufacturing is the close relationship to the parts and assembly allowing for quick and easy repairs or upgrades throughout the use of the PV system which can span well over 20 years (Skoczek et al., 2009).

The lifespan of a PV system is an important consideration for 3-D printing material choice. Throughout the duration of use of the PV system the PLA will be subjected to solar ultraviolet (UV) light causing some degradation and it has been shown that longterm UV exposure of PLA can cause the plastic to become brittle (Copinet et al., 2004). This was not found after 1 year of outdoor testing with the PV racking, most likely due to the fact that the majority of the rack is not directly exposed to sunlight. The same printed PLA was used in an outdoor hinge and found to become brittle after 2 years of use thus indicating that unprotected PLA should not be used for outdoor applications that span many years such as this one. The transition to brittle material characteristics is common in many polymers when subjected to prolonged UV light exposure (Gijsman et al., 1999). However, it has been shown that HDPE with additives can maintain a relatively constant elastic modulus and elongation at the yield stress meaning HDPE can resist the brittle 
transition observed (Mendes et al., 2003). HDPE filament is not common but can be successfully manufactured with a Recyclebot or any of a long list of pro-sumer filament extruders (Dynamics, 2014; FilaMaker, 2014; Filabot, 2014; Lyman, 2014; Filaab, 2014; Filastruder, 2014). This also has the added benefit of improved environmental impact (Kreiger et al., 2014). It has also been shown that HDPE responds more to temperature fluctuations than solar radiation (Satoto et al., 1997) meaning a material optimization may be possible for geographic location based on temperature profiles and insulating the plastic parts with a sealant could help. Depending on location, the elevated operating temperatures of PV modules may help regulate the temperature of the plastic by providing a consistent operating temperature and aid in the reduction of the degradation rate that can be accelerated due to cyclical temperatures (Satoto et al., 1997). More information on mechanical data for PLA is required to offer a more in-depth estimate of the strength but as shown over the course of one year of outdoor testing the X-wire system performed adequately.

The X-wire system only requires a basic wrench to tighten the bolts down to the brackets meaning it can be assembled and disassembled almost anywhere. In addition, the RepRap can print the wrench (gr0b, 2013). This also allows easy repairs for nearly anyone as compared to other PV systems and other energy generation technologies, such as wind power, where repairs are a notorious problem in the developing world and can be immensely challenging even in the United States (Faulkner, 2013). Open source designs of appropriate technology (Pearce, 2012) allow for instant collaboration throughout the world with just an exchange of information allowing rapid improvement and iterative performance enhancements. With this quick exchange of information it is possible to take advise from other users for repairs if desired.

When a retail product is typically purchased it serves one purpose and, usually, is set up for one use. This can become a problem for people that may wish to use it in a different environment and those who move locations. Since this new system is open-source and easily customizable it is possible to optimize the PV racking system for any location or application. For example, the 3-D printed parts may be printed or spray-painted in any color to blend into the surroundings better (in addition to providing UV protection discussed above). Should it be desired that the racking components be virtually invisible on the mounting site that can be obtained through color variations. With PV theft rising (Lawson, 2012) the value of reducing the visibility of the high-value racking is great with the new $\mathrm{X}$-wire system. In addition to the ability to hide the components easily the customizable nature of the X-wire design allows for geographical optimization of the system which has been shown in simulations to reflect a $20 \%$ efficiency increase on average (Wittbrodt et al., 2014).

While it has been presented that the overall cost of a PV system is decreasing and the relative cost of the BOS is increasing, this new racking system can reverse that effect since the racking costs are estimated to be about $10 \%$ of the PV materials itself instead of the 50-55\% currently. Using a low cost racking system will allow the subject of racking to be a non-concern when designing a PV array and the cost is so low the entire PV 
system can begin to reach an affordable level for all consumers.

While the RepRap can be an extremely useful tool to increase the standard of living in the developing world it is imperative to aid in the education of its' use in this goal. In addition, applications of 3-D printing similar to this can help adapt the technology from at-home RepRap to viable manufacturing method (Bateman and Cheng, 2007). This study explores the continued use of 3-D printing to provide more economic alternatives to conventional commercially available products, specifically PV module racking. An additional benefit to the use of 3-D printing will allow the proposed racking system to be customizable for the location in which it will be used allowing the PV system to be optimized beyond what common commercial racking can provide, resulting in even greater return on investment. Merging the 3-D printing process with solar can help erase current questions about the sustainability of the technology as well (Bertling et al., 2014). Consequently the RepRap has the potential to sustain its' operation by printing replacement parts for itself and continuing to provide the user with tools, toys, educational aids, and many other things.

In addition to the economic benefit to people wanting to adopt solar power, this racking system has enormous potential in the developing world. With a $1 \mathrm{~kW}$ PV array, an entire village could potentially have lights inside their dwellings drastically improving their standard of living. Beyond light bulbs (or LEDs), the addition of refrigeration, water pumps, and other appliances could greatly improve the sanitation in these areas as well as improving the ability to make better food. Even a RepRap 3-D printer is not out of consideration in the list of possible utilities since they only draw about 100 Watts while running, fewer if no heated bed is used.

\section{Conclusions}

This study has shown that entry-level 3-D printing is a viable option for manufacturing solar photovoltaic racking for developing world applications. PV has been shown previously to be a valuable technology for sustainable development, however the BOS costs have reduced deployment velocity. The results presented here show that the use of 3 -D printing to fabricate PV racking can reduce the racking cost by over $80 \%$ significantly improving the economic case for multi-module PV systems in the developing world. Due to the remote locations of rural developing areas a distributed manufacturing model fits well with attempts to jump start economic and standard of living improvements. The ability of RepRap printers for development appear to be particularly well suited as these 3-D printers can not only print out valuable components for renewable energy systems, but also the repair parts and tools necessary to maintain themselves.

\section{Acknowledgments}

The authors would like to acknowledge technical assistance from H. Shawbitz and 
support from the Michigan Initiative for Innovation and Entrepreneurship.

\section{References}

Acker, R. H. \& Kammen, D. M. (1996). "The quiet (energy) revolution: Analysing the dissemination of photovoltaic power systems in Kenya", Energy Policy, 24, 81111.

Asm. (2014). "Aluminum 6063-T5".

http://asm.matweb.com/search/SpecificMaterial.asp?bassnum=MA6063T5 (Accessed May 18 2014).

Baechler, C., Devuono, M. \& Pearce, J. M. (2013). "Distributed recycling of waste polymer into RepRap feedstock", Rapid Prototyping Journal, 19, 118-125.

Bateman, R. J. \& Cheng, K. (2007). "Rapid Manufacturing as a tool for agile manufacturing: application and implementation perspectives", International Journal of Agile Manufacturing, 9, 39-52.

Bertling, J., Blömer, J., Rechberger, M. \& Schreiner, S. (2014). "DDM-An Approach Towards Sustainable Production?", Young, 35, 30.

Branker, K., Pathak, M. J. M. \& Pearce, J. M. (2011). "A review of solar photovoltaic levelized cost of electricity", Renewable and Sustainable Energy Reviews, 15, 4470-4482.

Campbell, T., Williams, C., Ivanova, O. \& Garrett, B. (2011). "Could 3D Printing Change the World?", Technologies, Potential, and Implications of Additive Manufacturing. Washington, DC: Atlantic Council.

Chen, S. \& Ravallion, M. (2008). "The Developing World Is Poorer Than We Thought, But No Less Successful in the Fight against Poverty", Development Research.

Copinet, A., Bertrand, C., Govindin, S., Coma, V. \& Couturier, Y. (2004). "Effects of ultraviolet light (315 nm), temperature and relative humidity on the degradation of polylactic acid plastic films", Chemosphere, 55, 763-773.

Drennen, T. E., Erickson, J. D. \& Chapman, D. (1996). "Solar power and climate change policy in developing countries", Energy Policy, 24, 9-16.

Dugger, C. W. (2006). Toilets Underused to Fight Disease, U.N. Study Finds. The New York Times.

Dynamics, O. (2014). "Strooder". http://omnidynamics.co.uk/shop/strooder (Accessed July 30 2014).

Energy, D. O. (2010). Building Code. In: GROWTH, L. A. E. (ed.).

Faulkner, T. (2013). "No Easy Fix for Broken Wind Turbine at US High School". Renewable Energy World.

http://www.renewableenergyworld.com/rea/news/article/2013/05/no-easy-fix-forbroken-wind-turbine-at-us-high-school (Accessed July 22 2014).

Feeley, S. R., Wijnen, B., \& Pearce, J. M. (2014). Evaluation of Potential Fair Trade Standards for an Ethical 3-D Printing Filament. Journal of Sustainable Development, 7(5), 1-12.

Filaab. (2014). http://www.filafab.co.uk/ (Accessed July 30 2014).

Filabot. (2014). http://www.filabot.com/ (Accessed July 30 2014).

Filamaker. (2014). http://filamaker.eu/ (Accessed July 30 2014). 
Filastruder. (2014). http://www.filastruder.com/ (Accessed July 30 2014).

Fthenakis, V. \& Alsema, E. (2006). "Photovoltaics energy payback times, greenhouse gas emissions and external costs: 2004-early 2005 status", Progress in Photovoltaics: Research and Applications, 14, 275-280.

Gijsman, P., Meijers, G. \& Vitarelli, G. (1999). "Comparison of the UV-degradation chemistry of polypropylene, polyethylene, polyamide 6 and polybutylene terephthalate", Polymer Degradation and Stability, 65, 433-441.

Goalzero. (2014)."Boulder 30 Solar Panel". http://www.goalzero.com/p/21/boulder-30solar-panel (Accessed July 22 2014).

Gr0b. (2013). "Customizeable Wrench". Thingiverse. http://www.thingiverse.com/thing:47842 (Accessed July 29 2014).

Jones, R., Haufe, P., Sells, E., Iravani, P., Olliver, V., Palmer, C. \& Bowyer, A. (2011). "RepRap - the replicating rapid prototyper", Robotica, 29, 177-191.

Kanagawa, M. \& Nakata, T. (2008). "Assessment of access to electricity and the socioeconomic impacts in rural areas of developing countries", Energy Policy, 36, 2016-2029.

Keweenaw Research Center . (2014). "KRC Weather Station". http://www.mtukrc.org/weather.htm (Accessed July 27 2014).

Kreiger, M. A., Mulder, M. L., Glover, A. G. \& Pearce, J. M. (2014). "Life cycle analysis of distributed recycling of post-consumer high density polyethylene for 3-D printing filament", Journal of Cleaner Production, 70, 90-96.

Kruth, J. P., Leu, M. C. \& Nakagawa, T. (1998). "Progress in Additive Manufacturing and Rapid Prototyping", CIRP Annals - Manufacturing Technology, 47, 525-540.

Lawson, J. (2012). The PV Industry Tackles Solar Theft. Available from: http://www.renewableenergyworld.com/rea/news/article/2012/04/the-pv-industrytackles-solar-theft [Accessed July 22 2014].

Leu, M. C., Deuser, B. K., Tang, L., Landers, R. G., Hilmas, G. E. \& Watts, J. L. (2012). "Freeze-form extrusion fabrication of functionally graded materials", CIRP Annals - Manufacturing Technology, 61, 223-226.

Lewis, N. S. (2007). "Toward cost-effective solar energy use", Science, 315, 798-801.

Lipson, H. \& Kurman, M. (2013). Fabricated: The new world of 3D printing, John Wiley \& Sons.

Lyman, H. (2014). "Lyman Filament Extruder V4.1". http://www.thingiverse.com/thing:265375 (Accessed July 30 2014).

Mendes, L. C., Rufino, E. S., De Paula, F. O. C. \& Torres Jr, A. C. (2003). "Mechanical, thermal and microstructure evaluation of HDPE after weathering in Rio de Janeiro City", Polymer Degradation and Stability, 79, 371-383.

Mitsuishi, M., Cao, J., Bártolo, P., Friedrich, D., Shih, A. J., Rajurkar, K., Sugita, N. \& Harada, K. (2013). "Biomanufacturing", CIRP Annals - Manufacturing Technology, 62, 585-606.

MOST. (2014). "MOST RepRap Primer". http://www.appropedia.org/MOST_RepRap_Primer (Accessed January 23 2014).

Ochshorn, J. (2009). "Example 2.3: Find snow laods". https://courses.cit.cornell.edu/arch264/calculators/example2.3/ (Accessed July 29 
2014).

OpenSCAD. (2014).http://www.openscad.org (Accessed May 29 2014).

Pearce, J. M. (2002). "Photovoltaics — a path to sustainable futures", Futures, 34, 663674.

Pearce, J. M. (2012). "The case for open source appropriate technology", Environment, Development and Sustainability, 14, 425-431.

Pearce, J. M., Morris Blair, C., Laciak, K. J., Andrews, R., Nosrat, A. \& Zelenika-Zovko, I. (2010). "3-D Printing of Open Source Appropriate Technologies for SelfDirected Sustainable Development", Journal of Sustainable Development, 3.

Pham, D. T. \& Gault, R. S. (1998). "A comparison of rapid prototyping technologies", International Journal of Machine Tools and Manufacture, 38, 1257-1287.

Reiche, K., Covarrubias, A. \& Martinot, E. (2000). "Expanding electricity access to remote areas: off-grid rural electrification in developing countries", Fuel, 1, 1.4.

Repetier. (2014). http://www.repetier.com/ (Accessed January 23 2014).

Satoto, R., Subowo, W. S., Yusiasih, R., Takane, Y., Watanabe, Y. \& Hatakeyama, T. (1997). "Weathering of high-density polyethylene in different latitudes", Polymer Degradation and Stability, 56, 275-279.

Shah, A. (2013). "Poverty Facts and Stats". Global Issues. http://www.globalissues.org/article/26/poverty-facts-and-stats (Accessed July 29 2014).

Sharp. (2014). "Residential Products". http://www.sharpusa.com/SolarElectricity/SolarProducts/ResidentialSolarProduct s.aspx (Accessed July 22 2014).

Skoczek, A., Sample, T. \& Dunlop, E. D. (2009). "The results of performance measurements of field-aged crystalline silicon photovoltaic modules", Progress in photovoltaics: Research and Applications, 17, 227-240.

Tanenbaum, J. G., Williams, A. M., Desjardins, A. \& Tanenbaum, K. Democratizing technology: pleasure, utility and expressiveness in DIY and maker practice. Proceedings of the SIGCHI Conference on Human Factors in Computing Systems, 2013. ACM, 2603-2612.

Tymrak, B. M., Kreiger, M. \& Pearce, J. M. (2014). "Mechanical properties of components fabricated with open-source 3-D printers under realistic environmental conditions", Materials \& Design, 58, 242-246.

Ultimaker. (2014). http://wiki.ultimaker.com/Cura (Accessed March 17 2014).

Unirac. (2014). Unirac RM Technical Datasheet.

Wohlers Associates, W. (2013). Wohlers Report 2013: Additive Manufacturing and 3D Printing State of the Industry Executive Summary.

Wittbrodt, B., Laureto, J., Tymrak, B. and Pearce,J.M. (2014). “Distributed Manufacturing with 3- D Printing: A Case Study of Recreational Vehicle Solar Photovoltaic Mounting Systems” (to be published).

Wittbrodt, B. T., Glover, A. G., Laureto, J., Anzalone, G. C., Oppliger, D., Irwin, J. L. \& Pearce, J. M. (2013). "Life-cycle economic analysis of distributed manufacturing with open-source 3-D printers", Mechatronics, 23, 713-726.

Yan, X. \& Gu, P. (1996). "A review of rapid prototyping technologies and systems", Computer-Aided Design, 28, 307-318. 